\title{
Evaluation of stormwater micropollutant source control and end-of-pipe control strategies using an uncertainty-calibrated integrated dynamic simulation model
}

\author{
Vezzaro, Luca; Sharma, Anitha Kumari; Ledin, Anna; Mikkelsen, Peter Steen
}

Published in:

Journal of Environmental Management

Link to article, DOI:

10.1016/j.jenvman.2014.12.013

Publication date:

2015

Document Version

Peer reviewed version

Link back to DTU Orbit

Citation (APA):

Vezzaro, L., Sharma, A. K., Ledin, A., \& Mikkelsen, P. S. (2015). Evaluation of stormwater micropollutant source control and end-of-pipe control strategies using an uncertainty-calibrated integrated dynamic simulation model. Journal of Environmental Management, 151, 56-64. https://doi.org/10.1016/j.jenvman.2014.12.013

\section{General rights}

Copyright and moral rights for the publications made accessible in the public portal are retained by the authors and/or other copyright owners and it is a condition of accessing publications that users recognise and abide by the legal requirements associated with these rights.

- Users may download and print one copy of any publication from the public portal for the purpose of private study or research.

- You may not further distribute the material or use it for any profit-making activity or commercial gain

- You may freely distribute the URL identifying the publication in the public portal 


\title{
Title: Evaluation of stormwater micropollutant source control and end-of-pipe control strategies using an uncertainty-calibrated integrated dynamic simulation model
}

\author{
Authors: L. Vezzaro $^{1 *}$, A. K. Sharma ${ }^{1}$, A. Ledin ${ }^{1,2}$ and P.S Mikkelsen ${ }^{1}$
}

\author{
Affiliation: \\ ${ }^{1}$ Department of Environmental Engineering (DTU Environment), Technical University of \\ Denmark, Building 113, Miljoevej, 2800 Kgs. Lyngby, Denmark \\ 2 Current address: Department of Sustainable development, environmental science and \\ engineering (SEED) School of Architecture and Built Environment (ABE) Royal Institute of \\ Technology (KTH), SE-100 44 Stockholm, Sweden \\ * Corresponding author, e-mail luve@env.dtu.dk
}

\begin{abstract}
The estimation of micropollutant (MP) fluxes in stormwater systems is a fundamental prerequisite when preparing strategies to reduce stormwater MP discharges to natural waters. Dynamic integrated models can be important tools in this step, as they can be used to integrate the limited data provided by monitoring campaigns and to evaluate the performance of different strategies based on model simulation results. This study presents an example where six different control strategies, including both source-control and end-of-pipe treatment, were compared. The comparison focused on fluxes of heavy metals (copper, zinc) and organic compounds (fluoranthene). MP fluxes were estimated by using an integrated dynamic model, in combination with stormwater quality measurements. MP sources were identified by using GIS land usage data, runoff quality was simulated by using a conceptual accumulation/washoff model, and a stormwater retention pond was simulated by using a dynamic treatment model based on MP inherent properties. Uncertainty in the results was estimated with a pseudo-Bayesian method. Despite the great uncertainty in the MP fluxes estimated by the runoff quality model, it was possible to compare the six scenarios in terms of discharged MP fluxes, compliance with water quality criteria, and sediment accumulation. Source-control strategies obtained better results in terms of reduction of MP emissions, but all the simulated strategies failed in fulfilling the criteria based on emission limit values. The results presented in this study shows how the efficiency of MP pollution control strategies can be quantified by combining advanced modelling tools (integrated stormwater quality model, uncertainty calibration).
\end{abstract}


Vezzaro, L., Sharma, A. K., Ledin, A., \& Mikkelsen, P. S. (2015). Evaluation of stormwater micropollutant source control and end-of-pipe control strategies using an uncertainty-calibrated integrated dynamic simulation model. Journal of Environmental Management, $151,56-64$.

doi:10.1016/j.jenvman.2014.12.013

\section{Keywords}

Stormwater quality model; micropollutants; integrated model; uncertainty analysis; pollution control strategy

\section{Introduction}

The move towards a holistic approach in urban water management has increased the focus on stormwater quality management. The growing awareness of the potential non-wanted biological effects of stormwater discharges due to micropollutants (MP), including heavy metals and organic compounds (e.g. Eriksson et al., 2007; Kayhanian et al., 2008; WiumAndersen et al., 2011; Zgheib et al., 2012; Zhang et al., 2011) and the legal requirements for reducing the discharge of these substances (e.g. the Water Framework Directive (WFD EC,2000)) require extended monitoring campaigns, as well as development and implementation of strategies to control stormwater pollution. The collection of monitoring data to support these strategies is however affected by significant financial and technical limitations (see for example Ledin et al. 2013), as representative samples during stormwater discharges are costly and difficult to collect. Furthermore, MP are commonly found in low concentrations (in the range of $n g / 1-\mu \mathrm{g} / \mathrm{l}$ ), which are difficult to measure. Conversely, information on different MP sources can be retrieved using cartographic information (stored in GIS databases) that is commonly available at the municipality level. For each land usage it is possible to find MP release data in the existing literature, or using database systems supporting pollutant source mapping (e.g. Lützhøft et al., 2012; Revitt et al., 2013). Therefore integrated models which combine source characterization with measured data are essential tools to understand and analyze the behavior of complex stormwater systems and to evaluate different strategies to achieve desired water quality standards, as discussed for combined systems by Rauch et al. (2005).

A great number of integrated models have been developed, tested and applied in the last decade with main focus on combined sewer systems, whereas diffuse pollution loads deriving from separate systems and stormwater treatment have received little attention from modelers, with some relevant exceptions (see for example the review in Elliott and Trowsdale, 2007). Also, as discussed by Bertrand-Krajewski (2007), stormwater quality modeling is affected by significant sources of uncertainty, which may limit the application of these tools in practice. For example, Vezzaro et al. (2012) introduced an integrated model - combining MP source characterization with dynamic modeling of runoff quality and stormwater treatment. Due to lack of data, only the hydraulic submodel was calibrated. The use of uncertainty analysis techniques is therefore essential to assess the prediction bounds of the models. In this context, the Generalized Likelihood Uncertainty Estimation technique (GLUE - Beven and Binley, 1992) has increasingly been applied in stormwater quality modeling due to the limited 
Vezzaro, L., Sharma, A. K., Ledin, A., \& Mikkelsen, P. S. (2015). Evaluation of stormwater micropollutant source control and end-of-pipe control strategies using an uncertainty-calibrated integrated dynamic simulation model. Journal of Environmental Management, $151,56-64$. doi:10.1016/j.jenvman.2014.12.013

number of prior assumptions about the error structure involved (Freni et al., 2009). In this context, the term "uncertainty calibration" (Lindblom et al., 2011; McIntyre et al., 2002) has been coined for identifying "calibrated" (behavioral) parameter distributions that contain information about the model's predictive uncertainty, conditioned on the data used for calibration.

This study presents the uncertainty-calibration of the integrated model presented by Vezzaro et al. (2012) against water quality measurements, namely traditional quality parameters (Total Suspended Solids -TSS), heavy metals (copper - $\mathrm{Cu}-$ and Zinc $-\mathrm{Zn}$ ), and organic substances (fluoranthene - CAS 206-44-0). The uncertainty-based calibration increases the robustness of model-based evaluation of pollution reduction strategies, as urban water managers can include result uncertainty (often neglected) in the comparison of different realistic scenarios. A case study is used to represent a common situation in the urban water field, where limited water quality data are available and pollution control options need to be implemented. The presented results thus illustrate the flexibility of the proposed approach as support to urban water managers.

\section{Material and methods}

\subsection{The Albertslund case study}

The Hersted Industripark catchment is a 95 ha mixed industrial-residential catchment located in the Albertslund municipality (Denmark). Runoff is collected by a separate drainage network consisting of open channels in the downstream end and is treated in a retention pond (Basin K) before discharge to a stream (Figure 1). Several monitoring campaigns (Table 1) have been carried out in the catchment in order to assess the present stormwater quality. Stormwater composite samples were collected at the pond inlet (using a flow-proportional sampler) and at the outlet (using a time-proportional sampler). Samples were analyzed for TSS, heavy metals ( $\mathrm{Cu}$ and $\mathrm{Zn}$ ) and organic substances (fluoranthene - CAS 206-44-0). TSS was analyzed by filtering the sample through $1.5 \mathrm{~mm}$ Whatman ${ }^{\mathrm{TM}} 934-\mathrm{AH}^{\mathrm{TM}}$ glass microfiber filters and drying the filtrate remained on the filter at $105^{\circ} \mathrm{C}$. Total and dissolved $(0.45 \mu \mathrm{m}$ filter) $\mathrm{Cu}$ and $\mathrm{Zn}$ were analyzed using induced coupled plasma optical emission spectroscopy (ICP-OES). Fluoranthene was analyzed using the Gas Chromatography Mass Selective Detector (GC-MSD) by the commercial lab Højvang Miljølaboratorium A/S. 
Vezzaro, L., Sharma, A. K., Ledin, A., \& Mikkelsen, P. S. (2015). Evaluation of stormwater micropollutant source control and end-of-pipe control strategies using an uncertainty-calibrated integrated dynamic simulation model. Journal of Environmental Management, 151, 56-64.

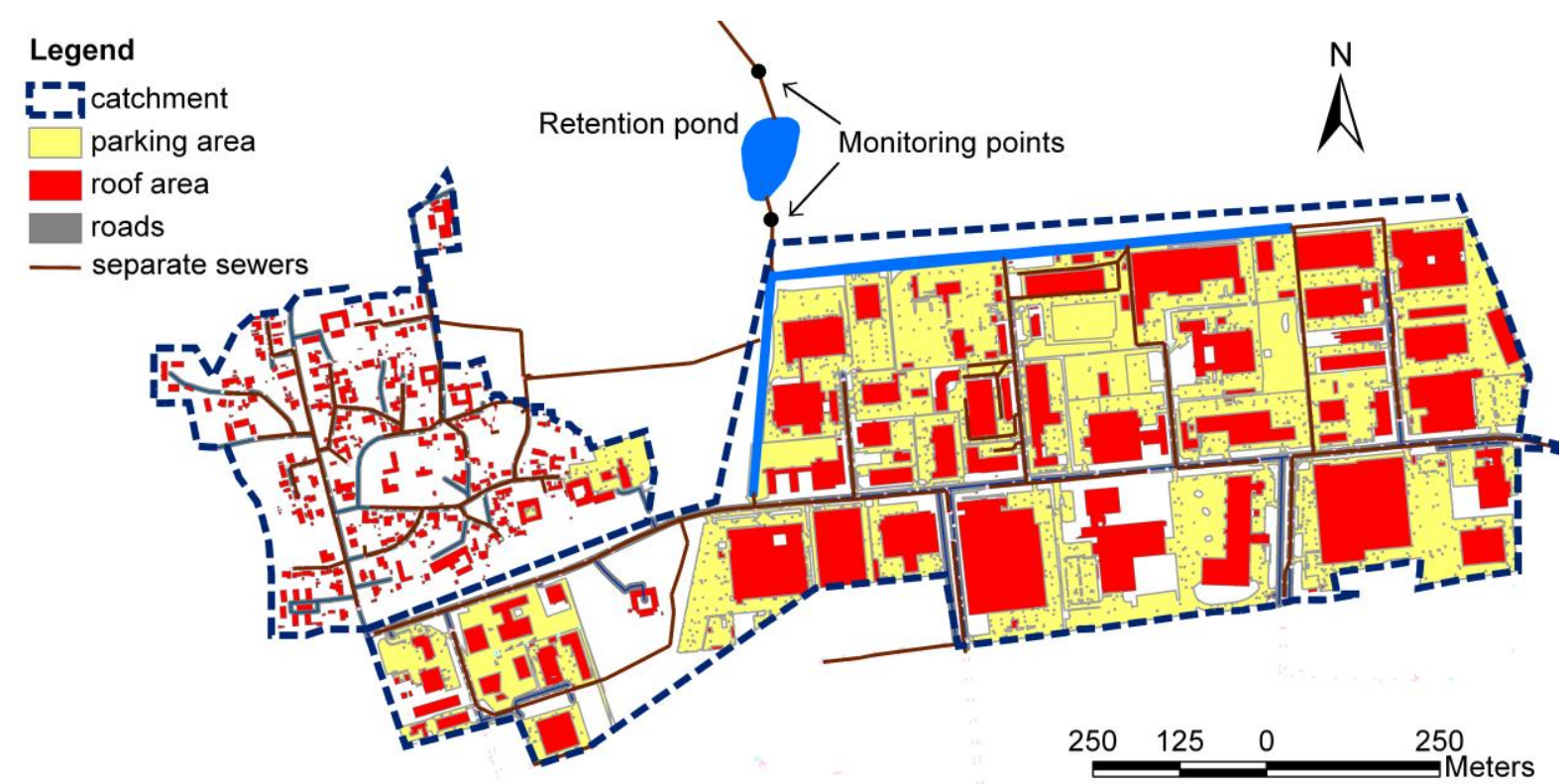

Figure 1. Characterization of the study area according to land usage (Vezzaro et al., 2012).

Table 1. Description of the measurements used in the uncertainty calibration.

\begin{tabular}{|c|c|c|c|c|c|c|}
\hline Data & Period & Resolution & No. of & vents & No. of & samples \\
\hline \multirow{2}{*}{$\begin{array}{l}\text { Inflow, } \\
\text { outflow }\end{array}$} & \multirow{2}{*}{$\begin{array}{l}2009 / 09 / 22- \\
2011 / 07 / 14^{\mathrm{a}}\end{array}$} & \multirow{2}{*}{$2 \mathrm{~min}$} & \multicolumn{2}{|l|}{216} & \multicolumn{2}{|l|}{ - } \\
\hline & & & $\overline{\mathrm{Cu}, \mathrm{Zn}}$ & $\mathrm{MP}^{\mathrm{b}}$ & $\mathrm{Cu}, \mathrm{Zn}$ & $\mathrm{MP}^{\mathrm{b}}$ \\
\hline Inlet quality & May 2011- May 2011 & Flow-proportional & $\overline{10}$ & 5 & $51^{\mathrm{d}}$ & $13^{\mathrm{c}}$ \\
\hline Outlet quality & $\begin{array}{l}\text { September -October } \\
2010\end{array}$ & Time proportional & 7 & 6 & 31 & $9^{c}$ \\
\hline
\end{tabular}

${ }^{a}$ Due to interruptions in monitoring and snow melting processes, the available measurements cover approximately 293 days; ${ }^{b}$ Fluoranthene; ${ }^{c}$ Composite samples obtained by three different bottles, ${ }^{d}$ some of the samples are composite samples.

\subsection{Pollution control strategies}

Six different scenarios were identified in collaboration with Albertslund municipality, to exemplify potential strategies for reducing the MP loads discharged to the aquatic environment downstream from Basin $\mathrm{K}$. These included a combination of different source control options and extended end-of-pipe treatment options, as outlined in Table 2 and elaborated below.

\subsubsection{Source control options}

- Scenario A: conversion of $50 \%$ of the industrial area to residential use. The composition of the new residential area (roofs, roads and other impervious areas) is obtained by analyzing the land usage data of a residential neighborhood with similar characteristics. 
Vezzaro, L., Sharma, A. K., Ledin, A., \& Mikkelsen, P. S. (2015). Evaluation of stormwater micropollutant source control and end-of-pipe control strategies using an uncertainty-calibrated integrated dynamic simulation model. Journal of Environmental Management, $151,56-64$. doi:10.1016/j.jenvman.2014.12.013

Two sub-scenarios are simulated: Scenario A1: where zinc gutters are allowed; and Scenario A2: where zinc gutters and metal roofs are not authorized in buildings.

- Scenario B: local treatment by infiltration of runoff from roads and parking areas into local swale-trench systems (wadi's). The discharge from these facilities is then conveyed to Basin K. The municipality requires detention of flows exceeding $1.5 \mathrm{l} / \mathrm{s} / \mathrm{ha}$, which are stored in the trench and released afterwards. A fixed MP removal rate is assumed in the local swale-trench treatment unit by using a conservative value of $60 \%$ for metals (this low value is assumed by combining the findings presented in Hatt et al. (2009) and Fassman (2012)) and 80\% for fluoranthene (DiBlasi et al., 2009).

- Scenario $C$ : disconnection of roof surfaces and local infiltration of roof runoff into groundwater. Two sub-scenarios are simulated: Scenario $C l$ considers only disconnection and infiltration of the roof in the industrial area, while Scenario $C 2$ considers all the roof surfaces in the catchment.

\subsubsection{End of pipe treatment options}

- Scenario D: increase of the pond depth. In Scenario D1 the depth is increased from $0.8 \mathrm{~m}$ to $1.2 \mathrm{~m}$, while in Scenario D2 the depth is increased to $1.7 \mathrm{~m}$.

- Scenario E: subdivision of the pond into three serial basins of equal volume. The total volume of the pond is not changed, while the depth of the first basin is increased by $0.5 \mathrm{~m}$ to increase settling.

- Scenario F: this scenario considers the effects of sediment resuspension caused by the fish population in the pond. These species are usually introduced by citizens for recreational purposes (fishing), unaware of the potential negative effect on the performance of the treatment unit. Sediment resuspension is calculated by assuming a total biomass of approximately $100 \mathrm{~kg}$ carp in the pond and by using a resuspension rate of $23 \mathrm{~g} / \mathrm{m}^{2}$ (Breukelaar et al., 1994).

\subsection{Integrated model}

The integrated model (Vezzaro et al., 2012) subdivides the stormwater drainage system into three elements: MP sources, catchment and drainage network, and treatment facilities. The inputs to the integrated quality model are rainfall intensities and MP release rates, which are estimated based on information obtained in the catchment characterization. To estimate the MP sources, the catchment is characterized into three different areas (Figure 1): roofs (with $5 \%$ of metal roofs - value defined according to typical values observed in similar catchments), roads, and other impervious areas (e.g. parking lots). This classification is based on cartographic information (stored in GIS databases) provided by the Albertslund municipality. For each land usage MP release data are available in the database developed by Lützhøft et al. (2009; 2012). 
Vezzaro, L., Sharma, A. K., Ledin, A., \& Mikkelsen, P. S. (2015). Evaluation of stormwater micropollutant source control and end-of-pipe control strategies using an uncertainty-calibrated integrated dynamic simulation model. Journal of Environmental Management, 151, 56-64.

doi:10.1016/j.jenvman.2014.12.013

Table 2. Summary of simulated pollution control scenarios.

Pollution control scenario

Source control

A1 Conversion to residential area (with zinc gutters)

A2 Conversion to residential area (without zinc gutters)

B Swale-trenches (wadi)

C1 Infiltration of roofwater (only from industrial areas)

C2 Infiltration of roofwater (from the entire catchment)

End-of-pipe treatment

D1 Increase of the pond water level from $0.8 \mathrm{~m}$ to $1.2 \mathrm{~m}$

D2 Increase of the pond water level from $0.8 \mathrm{~m}$ to $1.7 \mathrm{~m}$

E Subdivision of the pond

F Introduction of wildlife

The drainage network is modeled by using a dynamic runoff quality model: the catchment outflow is calculated with a non-linear reservoir approach while stormwater quality is simulated by using an accumulation-washoff model (see details in Vezzaro et al., 2012 and Vezzaro and Mikkelsen, 2012). Stormwater treatment is modeled by applying the Stormwater Treatment Unit model for MicroPollutants (STUMP - Vezzaro et al., 2010), a conceptual dynamic model which simulates the fate of various MP (subdivided into particulate and dissolved phase) in different treatment systems. MP fate processes (mostly affecting the MP dissolved phase) are simulated by using the pollutant inherent properties, using an approach which reduces the need for expensive MP monitoring campaigns.

To simulate the scenarios described in Section 2.2, some additional feature are added to the integrated model described in Vezzaro et al. (2012). The swale-trench (Scenario B) is modeled by using a tank removing a fixed fraction of the inlet MP concentration. For simplicity the various trenches placed across the catchment are lumped into a single unit for each land usage (roads, roofs, and other impervious). To simulate scenario E, three STUMP units are used to represent the subdivision of the pond. To simulate scenario $\mathrm{F}$, a constant mass flux between the sediment and the water compartments is added to the STUMP unit.

\subsection{Uncertainty calibration}

The uncertainty analysis focused on input and parameter uncertainty, assessed by applying the GLUE method of Beven and Binley (1992) for uncertainty calibration (McIntyre et al., 2002). The comparison presented in Dotto et al. (2012) showed that this approach provides equivalent results to other uncertainty estimation methods with lower computational costs. 
Vezzaro, L., Sharma, A. K., Ledin, A., \& Mikkelsen, P. S. (2015). Evaluation of stormwater micropollutant source control and end-of-pipe control strategies using an uncertainty-calibrated integrated dynamic simulation model. Journal of Environmental Management, $151,56-64$. doi:10.1016/j.jenvman.2014.12.013

The performance of the model is evaluated by using the following informal likelihood measure, based on the inverse residual variance (Beven and Freer, 2001):

$$
L\left[M\left(\theta_{i} \mid Y_{T}, Z_{T}\right)\right]=\left(\frac{1}{\sigma_{i}^{2}}\right)^{N}
$$

where $L$ is the informal likelihood of the realization of the model; $M\left(\theta_{i} \mid Y_{T}, Z_{T}\right)$ is the realization of the model $M$, based on the i-th parameter set $\theta_{i}$ and conditioned on input data $Y_{T}$ and on observed values $Z_{T}$; $N$ is a scaling factor, and $\sigma^{2}{ }_{i}$ is the variance of the residuals. Previous studies (Vezzaro and Mikkelsen, 2012) identified eq. 1 as most appropriate when using GLUE in combination with pollutographs. GLUE is applied to each submodel (catchment hydrological, catchment quality, STUMP hydraulic, and STUMP quality evaluated independently) by using an initial sample of 5000 parameter sets, which is further improved by applying the Shuffled Complex Evolution Metropolis algorithm (SCEM-UA Vrugt et al., 2003) to focus the sample in the regions of the parameter space which ensured better model performance..

To obtain a complete assessment of the prediction for each parameter set, the likelihood measures calculated for the simulated TSS $\left(L_{T S S}\right)$ and MP $\left(L_{M P}\right)$ concentration is combined by using the following formula:

$$
L_{\text {quality }}=L_{T S S} * L_{M P}
$$

The use of the combined informal likelihood listed in eq. 2 ensures a reduction of the uncertainty in the results of the STUMP submodel in situations when TSS measurements are available but MP data are scarce. (Vezzaro et al., 2011).

According to the GLUE procedure, a likelihood threshold $\gamma$ is used to distinguish the "behavioral" parameter sets, which are then used to generate the model prediction bounds. To define $\gamma$ in a tangible manner, $\gamma$ was set to cover a fraction of the observations within the $90 \%$ percentile prediction bounds (following the approach proposed by Blasone et al., 2008; and recently described in Vezzaro et al., 2013). This fraction (see Table 3) is defined by considering the characteristics of the observed data, their uncertainty, and the limitations of the model. The quality of the estimated prediction bounds is evaluated by calculating the Average Relative Interval Length (ARIL), which was introduced by Jin et al. (2010) as:

$$
A R I L=\frac{1}{N_{o b s}} \sum_{j=1}^{N_{o b s}} \frac{\text { Limit }_{\text {upper }, j}-\text { Limit }_{\text {lower }, j}}{Z_{T}\left(t_{j}\right)}
$$

where $N_{o b s}$ is the number of available observations; and Limit ${ }_{\text {upper }, j}$ and Limit ${ }_{\text {lower }, j}$ are the upper and lower prediction bounds at the time $t_{j}$. 
Vezzaro, L., Sharma, A. K., Ledin, A., \& Mikkelsen, P. S. (2015). Evaluation of stormwater micropollutant source control and end-of-pipe control strategies using an uncertainty-calibrated integrated dynamic simulation model. Journal of Environmental Management, 151, 56-64. doi:10.1016/j.jenvman.2014.12.013

\subsection{Evaluation and comparison of pollution control scenarios}

The integrated model is applied in this study to estimate the fluxes of TSS and MP over a 10year period and elaborate statistics regarding MP loads deriving from stormwater discharge. Input rainfall data (1-minute resolution) are retrieved from the database of historical rain series (Jørgensen et al., 1998) and covers the interval 1994-2004.

The integrated model is run to simulate the existing situation (baseline scenario) as well as the 6 potential scenarios. A total of 1000 parameter sets are randomly sampled from the behavioral parameter sets identified by the uncertainty calibration. These parameter sets are then used to run the model for each scenario: the obtained MP fluxes are thus based on these 1000 simulations. While the dynamic model runs with variable time steps (about seconds), outputs are saved at a 20-minute interval.

The outputs that are considered aimed at:

i. providing an overview of the current status of the system through the estimation of average yearly MP loads currently entering to and discharged from the retention pond;

ii. estimating the performance of different pollution control strategies in terms of MP loads discharged to the environment and MP accumulated in the pond sediments (information relevant for assessing the maintenance requirements of the system);

iii. evaluating the potential risk for the downstream aquatic environment based on the exceedance of Emission Limit Values (ELV). With respect to ELV for heavy metals, which are commonly targeting the dissolved form, the ability of STUMP to simulate dissolved MP is an essential feature. As ELV for the considered stormwater micropollutants are not available, Environmental Quality Standards (EQS) from existing Danish legislation (Danish Ministry of Environment, 2010) are used as substitute. EQS values are however defined for the receiving water body, i.e. they consider dilution after discharge. Thus, the comparison of the MP concentration against EQS would lead to conservative results.

\section{Results and discussion}

\subsection{Uncertainty calibration}

The detailed results of the GLUE analysis for the calibration period are listed in Table 3 . The different number of behavioral sets is affected by the shape of the likelihood response surfaces for different submodels and outputs. Steeper response surfaces (e.g. the one for the STUMP quality submodel) facilitated the convergence of the SCEM-UA algorithm, resulting in a greater number of behavioral sets. As shown in Vezzaro et al. (2012), input uncertainty caused the low coverage (about $40 \%$ ) of the runoff measurements. In fact, the rain gauge is located $3 \mathrm{~km}$ from the study area, resulting in incorrect estimations of the timing of the peak 
Vezzaro, L., Sharma, A. K., Ledin, A., \& Mikkelsen, P. S. (2015). Evaluation of stormwater micropollutant source control and end-of-pipe control strategies using an uncertainty-calibrated integrated dynamic simulation model. Journal of Environmental Management, $151,56-64$.

doi:10.1016/j.jenvman.2014.12.013

flows (for further details on the performance of the hydraulic submodel the reader is directed Vezzaro et al., 2012)

Table 3. Summary of results from uncertainty calibration of the different submodels.

\begin{tabular}{|c|c|c|c|c|c|c|}
\hline \multirow{3}{*}{\multicolumn{2}{|c|}{ Submodel }} & \multicolumn{3}{|c|}{ Covered observations [\%] } & \multirow{3}{*}{ ARIL } & Behavioral \\
\hline & & \multirow{2}{*}{$\begin{array}{l}\text { Acceptance } \\
\text { criterion }(\gamma)\end{array}$} & \multirow{2}{*}{\multicolumn{2}{|c|}{$\frac{\text { Effective Coverage }}{\text { flow }}$}} & & parameter \\
\hline & & & & & & sets [-] \\
\hline \multirow{3}{*}{\multicolumn{2}{|c|}{$\begin{array}{l}\text { Catchment - hydrologic } \\
\text { STUMP- hydraulic }\end{array}$}} & $>40$ & \multicolumn{2}{|c|}{40.3} & 1.21 & 785 \\
\hline & & $>40$ & \multicolumn{2}{|c|}{40.3} & 0.565 & 240 \\
\hline & & & TSS & MP & & \\
\hline \multirow{3}{*}{$\begin{array}{c}\text { Catchment } \\
\text { quality }\end{array}$} & $\mathrm{Cu}$ & $>66$ & 69.4 & 67.4 & 2.24 & 312 \\
\hline & $\mathrm{Zn}$ & $>75$ & 75.5 & 79.6 & 2.20 & 226 \\
\hline & Fluoranthene & $>66$ & 70.8 & 75.0 & 2.91 & 764 \\
\hline \multirow{3}{*}{$\begin{array}{l}\text { STUMP } \\
\text { quality }\end{array}$} & $\mathrm{Cu}$ & $>50$ & 63.4 & 52.0 & 0.421 & 3775 \\
\hline & $\mathrm{Zn}$ & $>40$ & 46.2 & 42.3 & 0.464 & 2708 \\
\hline & Fluoranthene & $>33$ & 33.3 & 66.7 & 0.160 & 407 \\
\hline
\end{tabular}

${ }^{\mathrm{a}}$ for discussion of uncertainty in flow predictions see Vezzaro et al. (2012).

The prediction bounds for the pond inlet concentrations (Figure 2) are affected by the by high concentrations recorded in one event (Figure 2a,d) with concentrations up to $840 \mu \mathrm{g} / \mathrm{l}$ for $\mathrm{Cu}$, $2761 \mu \mathrm{g} / \mathrm{l}$ for $\mathrm{Zn}$, and $1425 \mathrm{mg} / \mathrm{l}$ for TSS, likely caused by sediment resuspension in the open channels upstream from the pond inlet. These measurements influence the identification of behavioral parameter sets and thus explain the wide bounds for the first event (with ARIL above 2) and the significant overestimation of concentrations for other events (e.g. Figure $2 \mathrm{~b}, \mathrm{e})$. More than $66 \%(\mathrm{Cu}$, fluoranthene) and $75 \%(\mathrm{Zn})$ of the observed values are included within the prediction bounds.

The STUMP submodel shows comparatively narrower prediction bounds for the pond outlet (with ARIL around 0.4, e.g. Figure 3), but it covers a smaller part of the observations. This low coverage is mainly caused by the structural limitation of the model, which encounters difficulties in representing the hydraulic short circuiting of the pond during high flows. The simulated outlet concentrations shows in fact a temporal shift compared to the observed values (e.g. Figure 3a,c), resulting in a low coverage of observations. The magnitude of the simulated concentration is however similar to the observed values. To improve model predictions, preferential flows in the pond might be modeled by introducing a main channel and a Zone of Diminished Mixing, as in the serial tank configuration presented by Jansons et al. (2005). This would reduce the delay in the simulated concentrations when compared to the observed values. 
Vezzaro, L., Sharma, A. K., Ledin, A., \& Mikkelsen, P. S. (2015). Evaluation of stormwater micropollutant source control and end-of-pipe control strategies using an uncertainty-calibrated integrated dynamic simulation model. Journal of Environmental Management, 151, 56-64.
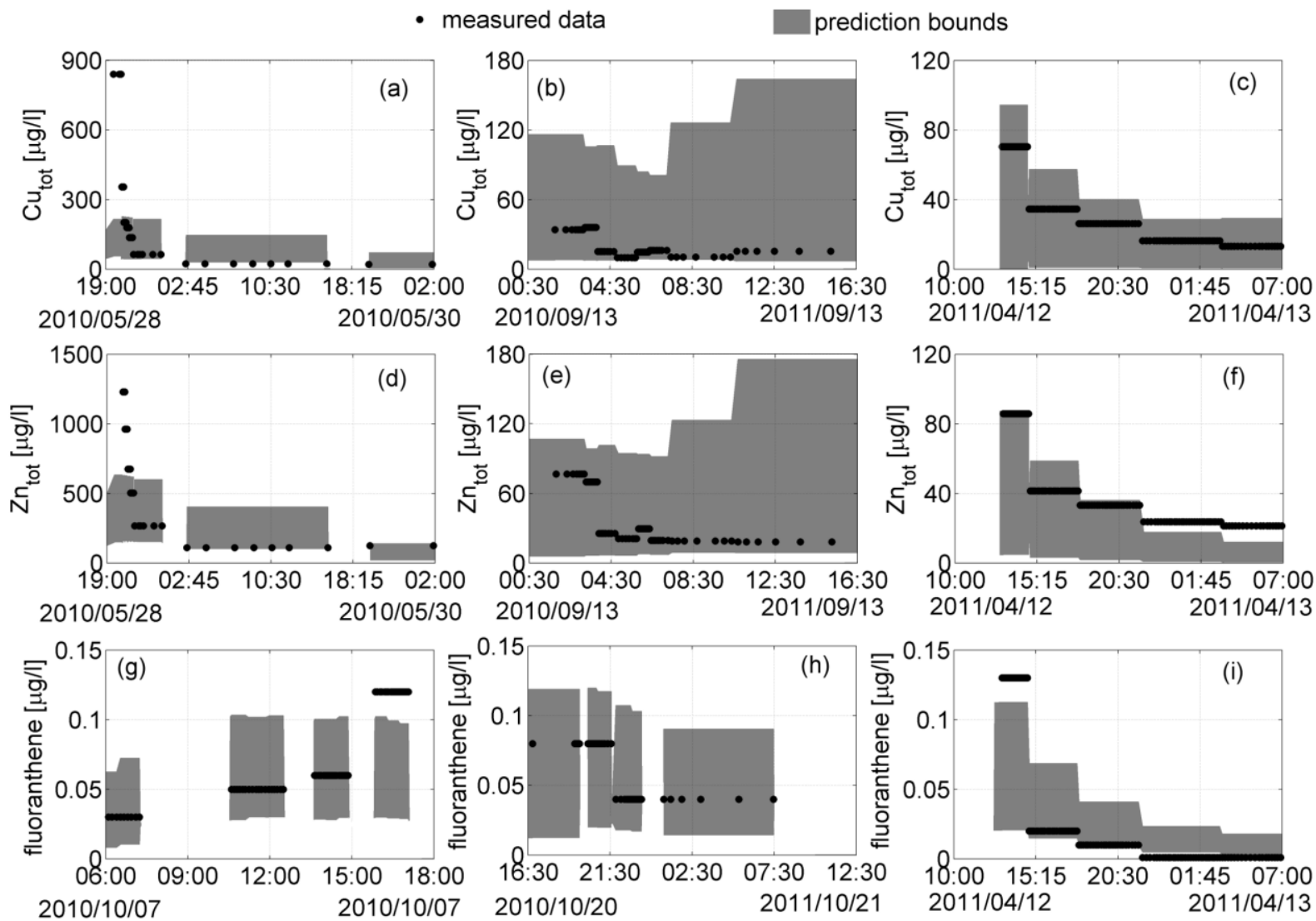

Figure 2. Measured pond inlet concentrations (black dots) and simulated values (grey area showing the 5\% and $95 \%$ bounds of the simulated samples) for $\mathrm{Cu}(\mathrm{a}, \mathrm{b}, \mathrm{c}), \mathrm{Zn}(\mathrm{d}, \mathrm{e}, \mathrm{f})$ and fluoranthene $(\mathrm{g}, \mathrm{h}, \mathrm{i})$ for three different events. The events shown for heavy metals differ from those for fluoranthene due to problems in sampling 
Vezzaro, L., Sharma, A. K., Ledin, A., \& Mikkelsen, P. S. (2015). Evaluation of stormwater micropollutant source control and end-of-pipe control strategies using an uncertainty-calibrated integrated dynamic simulation model. Journal of Environmental Management, $151,56-64$.
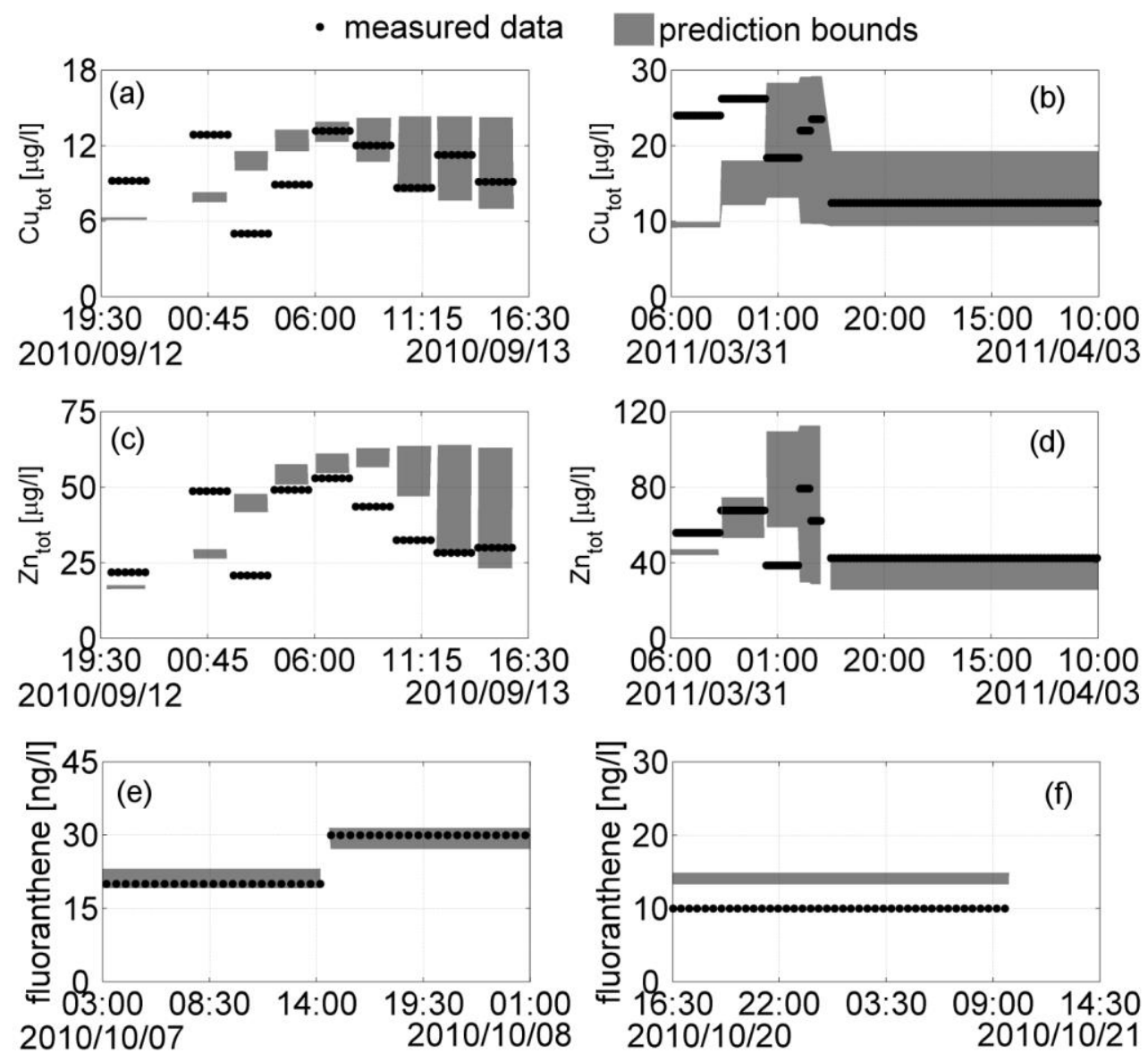

Figure 3. Measured pond outlet concentrations (black dots) and simulated values (grey area showing the $5 \%$ and $95 \%$ bounds of the simulated samples) for $\mathrm{Cu}(\mathrm{a}, \mathrm{b}), \mathrm{Zn}(\mathrm{c}, \mathrm{d})$ and fluoranthene $(e, f)$. The events shown for heavy metals differ from those for fluoranthene due to problems in sampling

Analytical uncertainty in the quality measurements and potential interactions between the various submodels (e.g. between the hydrological and the quality catchment submodels) are not explicitly considered in this study. Nevertheless, those sources of uncertainty represent an important aspect that needs to be addressed by further research, as they can contribute to a better evaluation of the model uncertainty. A thorough evaluation of uncertainty regarding fluoranthene is limited by the low number of available measurements. However, the simulation results are considered as sufficiently reliable for the scenario analysis, as $75 \%$ and $67 \%$ of the measured values are within the simulated bounds.

\subsection{Comparison of pollution control scenarios}

\subsubsection{Current status of the system}

Figure 4 shows the MP fluxes for the baseline scenario, providing an overview of the main removal processes and the fate of the different MP in the current system. The major removal 
Vezzaro, L., Sharma, A. K., Ledin, A., \& Mikkelsen, P. S. (2015). Evaluation of stormwater micropollutant source control and end-of-pipe control strategies using an uncertainty-calibrated integrated dynamic simulation model. Journal of Environmental Management, 151, 56-64.

doi:10.1016/j.jenvman.2014.12.013

process for the two heavy metals is settling (as indicated by the great accumulation in sediments), while other degradation processes played a role for fluoranthene (as suggested by the low simulated sediment accumulation rate). Interestingly, despite the different removal processes, all the MP showed similar removal rates in the retention pond (see Supplementary information).

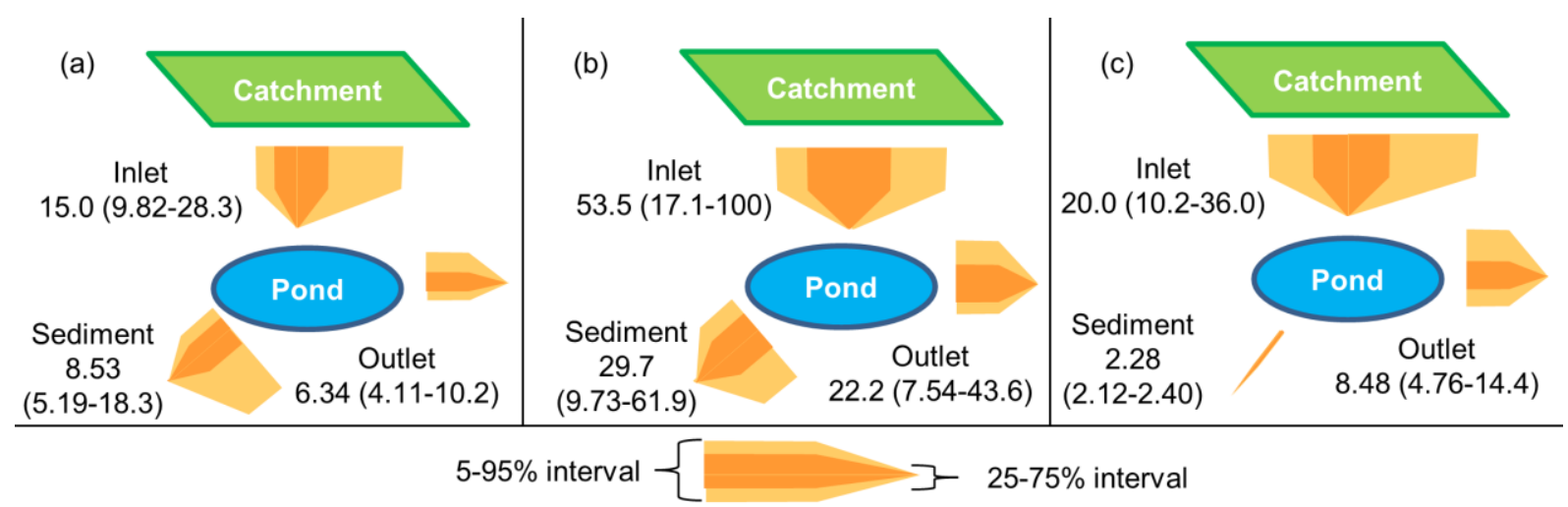

Figure 4. Simulated MP fluxes (median values) in the study area for the baseline scenario: (a) $\mathrm{Cu}\left[\mathrm{kg}_{\mathrm{Cu}} / \mathrm{yr}\right]$, (b) $\mathrm{Zn}\left[\mathrm{kg}_{\mathrm{Cu}} / \mathrm{yr}\right]$, and (c) fluoranthene $\left[\mathrm{g}_{\text {fluoranthene }} / \mathrm{yr}\right]$. Values in brackets show the $5-95 \%$ interval. Darker arrows show the $25-75 \%$ interval.

\subsubsection{Pollutant loads discharged to the aquatic environment}

The simulated yearly pollutant loads for the baseline (also described in Section 3.2.1) and the six future scenarios are shown in the supplementary information. Despite the wide prediction bounds (mainly due to the high uncertainty of the catchment quality submodel) it is possible to draw some general conclusions regarding the different scenarios by looking at the simulated relative reduction (shown in Figure 5). Several scenarios show overlapping reductions, suggesting that it is not possible to clearly distinguish their effect and thus that they will provide similar performance in terms of MP load reduction. Source control options generally provide a greater reduction in MP loads at the pond outlet than end-of-pipe treatment options, with some variation depending on simulated MP and scenario. The implementation of swale-trench systems (B) and the disconnection of all the roofs in the catchment $(\mathrm{C} 2)$ provide the greatest load reduction for all the three simulated substances. Fluoranthene and copper show similar patterns, with scenario B and C2 obtaining higher reduction than all the other scenarios. The load reductions obtained for scenario B is 10-20\% lower than the simulated removal rates in the trenches $(60 \%$ for $\mathrm{Cu}$ and $\mathrm{Zn}, 80 \%$ for fluoranthene). This is partly caused by the resuspension of polluted sediments in the pond during big rain events (i.e. when swales are saturated and no reduction in water volume is achieved).

Metallic roofs and zinc gutters are the major source of $\mathrm{Zn}$ in the catchment: the greater reduction in $\mathrm{Zn}$ loads are thus obtained when dealing with these sources (scenario $\mathrm{C} 2, \mathrm{~A} 2$ and 
Vezzaro, L., Sharma, A. K., Ledin, A., \& Mikkelsen, P. S. (2015). Evaluation of stormwater micropollutant source control and end-of-pipe control strategies using an uncertainty-calibrated integrated dynamic simulation model. Journal of Environmental Management, 151, 56-64. doi:10.1016/j.jenvman.2014.12.013

$\mathrm{C} 1$, in order of efficiency). As all the remaining scenarios (source-control and end-of-pipe treatment) obtain similar performance, the prioritization of the possible pollution control strategy cannot be based only on the expected reduction in MP loads, but should include additional criteria (such as effect on maintenance, as discussed in the next paragraphs). The presence of fish in the pond (scenario $\mathrm{F}$ ) is expected to increase the heavy metal loads by a maximum of $10 \%$, while no significant effect is expected for fluoranthene, as this MP is degraded and it is not affected by sediment resuspension.
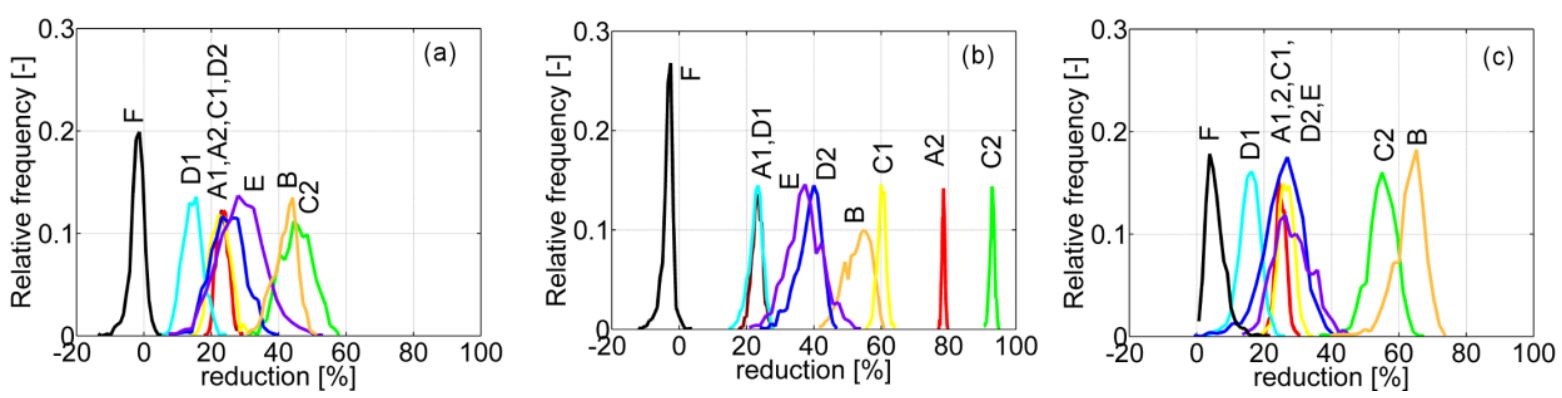

Figure 5. Reduction of estimated MP (total) loads to the environment relative to the baseline scenario for $\mathrm{Cu}(\mathrm{a}), \mathrm{Zn}(\mathrm{b})$ and fluoranthene (c).

\subsubsection{MP accumulation in the pond}

Figure 6 shows the yearly MP mass accumulated in the pond sediments over 10 years. In the majority of the source-control scenarios, no significant reduction in the total sediment mass is noticed: the decrease in the inlet loads due to source reduction is in fact compensated by better settling condition in the pond (i.e. less particles escaping the pond and greater sediment accumulation). This is especially noticed for scenarios $\mathrm{C}$, where catchment disconnection contributes to significantly reducing the hydraulic overload of the pond, increasing the overall treatment efficiency. Overall, all the scenarios (excluded B, where the inlet loads are significantly reduced and the effect of settling is thus limited) increase the pond removal efficiency (see the supplementary information). Clearly, scenarios focusing on enhanced treatment (D, E) results in an increased amount of MP in the sediments. For example, the greater residence time in scenario D2 and the lower sediment resuspension result in an increasing fraction of fluoranthene being sorbed to particles and subsequently removed by settling processes. The presence of fish in the pond $(\mathrm{F})$ did not result in major changes in the MP accumulated in the sediments. These results provide important information for evaluating the maintenance requirements of the different simulated scenarios. 
Vezzaro, L., Sharma, A. K., Ledin, A., \& Mikkelsen, P. S. (2015). Evaluation of stormwater micropollutant source control and end-of-pipe control strategies using an uncertainty-calibrated integrated dynamic simulation model. Journal of Environmental Management, 151, 56-64.

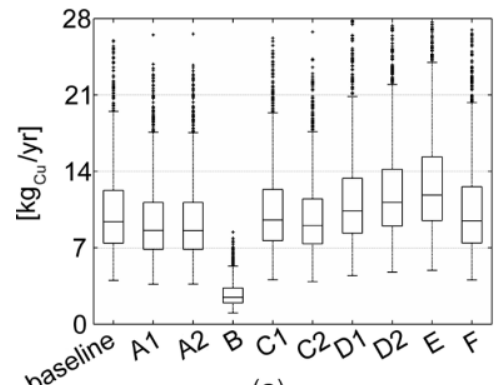

(a)

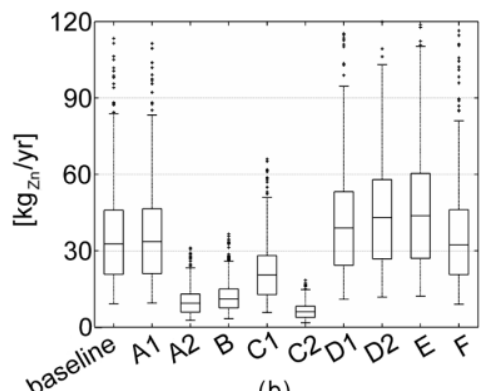

(b)

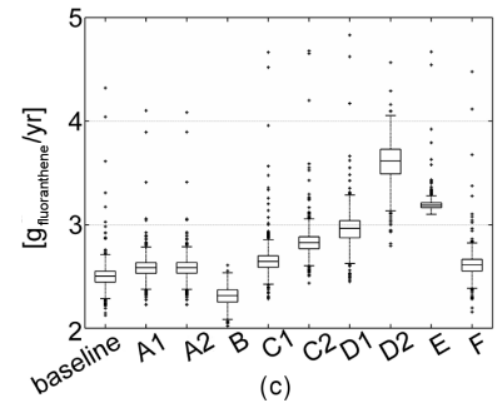

(c)

Figure 6. Simulated yearly MP mass (total) accumulated in the pond sediment over a 10-year period: $\mathrm{Cu}(\mathrm{a}), \mathrm{Zn}(\mathrm{b})$ and fluoranthene (c).

\subsubsection{Compliance with Emission Limit Values}

Figure 7 illustrates the simulated event mean concentrations at the pond outlet for different return periods (baseline scenario). From this chart is possible to evaluate the frequency of exceedance of an ELV for the simulated MP over the 10-year simulation period. Figure 7 shows that the ELV for both dissolved $\mathrm{Cu}$ and $\mathrm{Zn}$ are exceeded by more than $90 \%$ of the simulated parameter sets. Conversely, the ELV for fluoranthene is exceeded only during a single event (i.e. the exceedance frequency is lower than $0.1 \mathrm{yr}^{-1}$ ). From these results, dissolved $\mathrm{Cu}$ and $\mathrm{Zn}$ are expected to pose a risk to the downstream environment. However, this is a conservative assessment, as dilution in the receiving waters is not considered in this study.
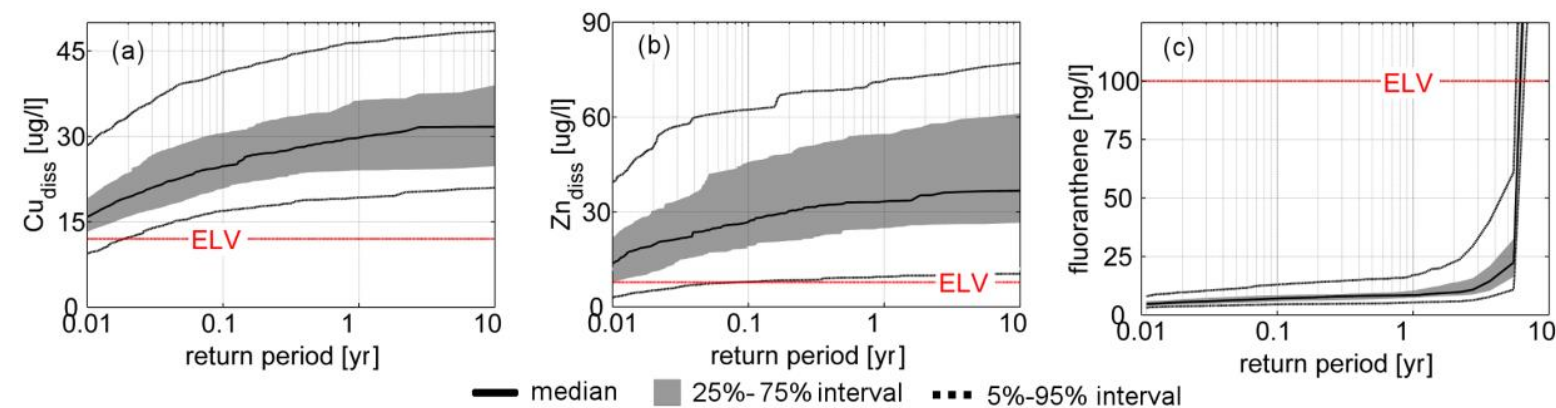

Figure 7. Simulated outlet event mean concentrations (EMC) against return period compared with ELV, for dissolved Cu (a - ELV $12 \mu \mathrm{g} / 1)$, dissolved Zn (b-ELV $7.8 \mu \mathrm{g} / \mathrm{l})$ and fluoranthene (c - ELV $0.1 \mu \mathrm{g} / \mathrm{l}$ ), for the baseline scenario.

Given that the major removal process for $\mathrm{Cu}$ and $\mathrm{Zn}$ is settling (section 3.2.1.), the dissolved fraction of $\mathrm{Cu}$ and $\mathrm{Zn}$ are not significantly affected by any of the simulated scenarios (see also the loads of dissolved MP listed in supplementary information). Therefore, none of the simulated scenarios succeeds in reducing the frequency of ELV exceedance to an acceptable level. The important reductions in MP loads obtained for the source control scenarios A2 and C2 (where EMC are reduced of about one third) are not sufficient to decrease EMCs below the desired value (see supplementary information). For example, the ELV for dissolved $\mathrm{Zn}$ is 
Vezzaro, L., Sharma, A. K., Ledin, A., \& Mikkelsen, P. S. (2015). Evaluation of stormwater micropollutant source control and end-of-pipe control strategies using an uncertainty-calibrated integrated dynamic simulation model. Journal of Environmental Management, $151,56-64$. doi:10.1016/j.jenvman.2014.12.013

exceeded by more than $50 \%$ of the simulations with a frequency greater than 10 times/yr in both scenario A2 (Figure S4a) and C2 (Figure S4b).

The simulation results thus suggest that additional pollution control strategies, specifically targeting dissolved fractions (e.g. filters at the pond outlet, such as the one presented in Vollertsen et al., 2009), may be included in potential scenarios for pollution control. Also, further development of the catchment quality sub-model to include phase distribution might improve the assessment of the different strategies with regards to the dissolved MP phase.

\subsubsection{Overall assessment}

By comparing the results illustrated in the previous paragraphs, source-control appears to be the most effective strategy to reducing the impact on receiving waters caused by stormwater discharges. Namely, scenario B (swale-trench systems) and C2 (disconnection of all the roofs) provided the greater benefits for all the three simulated MP. All the end-of-pipe scenarios do not provide important improvements compared to the baseline scenarios (and they will require additional maintenance due to major sediment accumulation). These results, which are based on an innovative approach that considers both model uncertainty and pollutant fate distribution, can be further supported by looking at field studies. For example, in the study presented by Bressy et al. (2012), treatment close to pollutant sources (i.e. the approach applied in scenario B) is suggested.

Scenario uncertainty (e.g. the simplified model used to represent swale trenches) might affect the scenario comparison and the final ranking of the pollution control strategies. Similarly, detailed hydrodynamic models can be used to evaluate the effect of the changes in pond configuration (deepening of the unit, subdivision into sub-basins), before implementation in the conceptual model.

This evaluation is however based only on MP load reduction, and should be combined with additional considerations regarding, among others, nutrient loads, construction and maintenance costs, social acceptance, technical and financial feasibility. The analysis of these factors is however beyond the scope of this paper.

\section{Conclusions}

The investigations presented in this study illustrate the potential for the application of integrated dynamic models as tools to evaluate pollution control strategies dealing with discharge of stormwater micropollutants. This study shows that:

- The integrated dynamic model presented in Vezzaro et al., (2012) is tested against MP concentration measurements. The catchment quality submodel shows great uncertainty, while structural model uncertainty is suggested for the pond submodel.

- The result uncertainty can be overcome by applying uncertainty calibration methods, which can be used to compare different scenario for MP control strategies, ranging 
Vezzaro, L., Sharma, A. K., Ledin, A., \& Mikkelsen, P. S. (2015). Evaluation of stormwater micropollutant source control and end-of-pipe control strategies using an uncertainty-calibrated integrated dynamic simulation model. Journal of Environmental Management, 151, 56-64.

from source control to end-of-pipe scenarios. Thanks to this approach, urban water managers can benefit of otherwise unreliable modelling results as support in their decision process.

- The presented integrated model enable (i) the identification of the fate of different MP in stormwater systems, (ii) the impact of different pollution control strategies on the MP fluxes across the system (e.g. on sediment accumulation), and (iii) on the receiving water body (by e.g. looking at the effect on MP dissolved concentrations). This is a significant improvement compared to previously available stormwater quality models.

- The case study presented in this article shows how the proposed integrated model can simulate different pollution control strategies, for micropollutants with different properties (copper, zinc, and fluoranthene) and for different species (dissolved and particulate). The comparison uses a limited amount of available measurements, which is a common situation in the urban water modelling field. Specifically, source-control strategies proved to be the most effective for the Albertslund catchment for the considered micropollutants.

\section{Acknowledgments}

Partial funding was received from the Interreg IVB North Sea Region Programme via the project "Impact of Climate Change on the Quality of Urban and Coastal Waters (Diffuse Pollution) - DiPOL". The authors show their gratitude to Hans-Henrik Høg (Albertslund municipality), Thomas Aabling and Søren Gabriel (Orbicon A/S) for providing the catchment data and flow measurements used in this study.

\section{References}

Bertrand-Krajewski,J.L., 2007. Stormwater pollutant loads modeling: Epistemological aspects and case studies on the influence of field data sets on calibration and verification. Water Sci. Technol., 55, 1-17.

Beven,K., Binley,A., 1992. Future of distributed models: Model calibration and uncertainty prediction. Hydrol. Process., 6, 279-298.

Beven,K.J., Freer,J.E., 2001. Equifinality, data assimilation, and uncertainty estimation in mechanistic modeling of complex environmental systems using the GLUE methodology. J. Hydrol., 249, 11-29. 
Vezzaro, L., Sharma, A. K., Ledin, A., \& Mikkelsen, P. S. (2015). Evaluation of stormwater micropollutant source control and end-of-pipe control strategies using an uncertainty-calibrated integrated dynamic simulation model. Journal of Environmental Management, $151,56-64$. doi:10.1016/j.jenvman.2014.12.013

Blasone,R.S., Vrugt,J.A., Madsen,H., Rosbjerg,D., Robinson,B.A., Zyvoloski,G.A., 2008. Generalized Likelihood Uncertainty Estimation (GLUE) Using Adaptative Markov Chain Monte Carlo Sampling. Adv. Water Res., 31, 630-648.

Bressy,A., Gromaire,M.C., Lorgeoux,C., Saad,M., Leroy,F., Chebbo,G., 2012. Towards the determination of an optimal scale for stormwater quality management: Micropollutants in a small residential catchment. Water Res., 46. 6799-6810.

Breukelaar,A.W., Lammens,E.H.R.R., Breteler,J.G.P.K., Tatrai,I., 1994. Effects of Benthivorous Bream (Abramis-Brama) and Carp (Cyprinus-Carpio) on Sediment Resuspension and Concentrations of Nutrients and Chlorophyll-A. Freshwater Biol., 32. 113121.

Danish Ministry of Environment, 2010. Bekendtgørelse om miljøkvalitetskrav for vandområder og krav til udledning af forurenende stoffer til vandløb, søer eller havett (Announcement on environmental quality requirements for water areas and criteria for discharge of pollutants in rivers, lakes and sea). BEK nr 1022 af 25/08/2010. 2010 (in Danish)

DiBlasi,C.J., Houng,L., Davis,A.P., Ghosh,U., 2009. Removal and Fate of Polycyclic Aromatic Hydrocarbon Pollutants in an Urban Stormwater Bioretention Facility. Environ. Sci. Technol., 43. 494-502.

Dotto,C.B.S., Mannina,G., Kleidorfer,M., Vezzaro,L., Henrichs,M., McCarthy,D.T., Freni,G., Rauch,W., Deletic,A., 2012. Comparison of different uncertainty techniques in urban stormwater quantity and quality modelling. Water Res., 46. 2545-2558.

Elliott,A.H., Trowsdale,S.A., 2007. A review of models for low impact urban stormwater drainage. Environ. Modell. Softw., 16. 195-231.

Eriksson,E., Baun,A., Mikkelsen,P.S., Ledin,A., 2007. Risk assessment of xenobiotics in stormwater discharged to Harrestrup Å, Denmark. Desalination, 215. 187-197.

European Commission, 2000. Directive 2000/60/EC of the European Parliament and of the Council of 23 October 2000 establishing a framework for Community action in the field of water policy. 2000/60/EC.

Fassman,E., 2012. Stormwater BMP treatment performance variability for sediment and heavy metals. Sep. Purif. Technol., 84, 95-103.

Freni,G., Mannina,G., Viviani,G., 2009. Urban runoff modeling uncertainty: Comparison among Bayesian and pseudo-Bayesian methods. Environ. Modell. Softw., 24. 1100-1111. 
Vezzaro, L., Sharma, A. K., Ledin, A., \& Mikkelsen, P. S. (2015). Evaluation of stormwater micropollutant source control and end-of-pipe control strategies using an uncertainty-calibrated integrated dynamic simulation model. Journal of Environmental Management, $151,56-64$. doi:10.1016/j.jenvman.2014.12.013

Hatt,B.E., Fletcher,T.D., Deletic,A., 2009. Pollutant removal performance of field-scale stormwater biofiltration systems. Water Sci. Technol., 59. 1567-1576.

Jansons, K., German, J., Howes, T., 2005. Evaluating hydrodynamic behavior and pollutant removal in various stormwater treatment pond configurations. In proceedings of the 10th International Conference on Urban Drainage (10ICUD), Copenhagen, Denmark, 21st -26th August 2005.

Jin,X., Xu,C.-Y., Zhang,Q., Singh,V.P., 2010. Parameter and modeling uncertainty simulated by GLUE and a formal Bayesian method for a conceptual hydrological model. J. Hydrol., 383. $147-155$.

Jørgensen,H.K., Rosenørn,S., Madsen,H., Mikkelsen,P.S., 1998. Quality control of rain data used for urban runoff systems. Water Sci. Technol., 37, 113-120.

Kayhanian,M., Stransky,C., Bay,S., Lau,S.-L., Stenstrom,M.K., 2008. Toxicity of urban highway runoff with respect to storm duration. Sci. Total Environ., 389, 386-406.

Ledin,A., Eriksson,E., Hörsing,M., Lützhøft,H.-C.H., Andersen,H.R., Hollender,J., Krauss,M., 2013. Sampling, Sample Preparation and Storage. C. Specific Analytical Methods. In: Düring,R.-A., Hummel, H., Gaith, S., Ledin, A. (Eds.), Handbook of environmental analysis. Wiley-VCH.

Lindblom,E., Ahlman,S., Mikkelsen,P.S., 2011. Uncertainty-based calibration and prediction with a stormwater surface accumulation-washoff model based on coverage of sampled Zn, $\mathrm{Cu}, \mathrm{Pb}$ and $\mathrm{Cd}$ field data. Water Res., 45, 3823-3835.

Lützhøft,H.-C.H., Donner,E., Wickman,T., Eriksson,E., Banovec,P., Mikkelsen,P.S., Ledin,A., 2012. A source classification framework supporting pollutant source mapping, pollutant release prediction, transport and load forecasting, and source control planning for urban environments. Environ. Sci. Pollut. R., 19, 1119-1130.

Lützhøft, H.-C. H., Eriksson, E., Donner, E., Wickmann, T., Banovec, P., Mikkelsen, P. S., Ledin, A. 2009, Quantifying releases of priority pollutants from urban sources. In proceedings of WEFTEC 09, 82nd Annual Water Environment Federation Technical Exhibition and Conference, October 10th -14th, Orlando, Florida, USA, 5873-5891.

McIntyre,N., Wheater,H., Lees,M., 2002. Estimation and propagation of parametric uncertainty in environmental models. J. Hydroinform., 4, 177-198. 
Vezzaro, L., Sharma, A. K., Ledin, A., \& Mikkelsen, P. S. (2015). Evaluation of stormwater micropollutant source control and end-of-pipe control strategies using an uncertainty-calibrated integrated dynamic simulation model. Journal of Environmental Management, $151,56-64$. doi:10.1016/j.jenvman.2014.12.013

Rauch,W., Seggelke,K., Brown,R., Krebs,P., 2005. Integrated Approaches in Urban Storm Drainage: Where Do We Stand? Environ. Manage., 35, 396-409.

Revitt,D.M., Lundy,L., Eriksson,E., Viavattene,C., 2013. Comparison of pollutant emission control strategies for cadmium and mercury in urban water systems using substance flow analysis. J. Environ. Manage., 116, 172-180.

Vezzaro,L., Mikkelsen,P.S., 2012. Application of global sensitivity analysis and uncertainty quantification in dynamic modeling of micropollutants in stormwater runoff. Environ.

Modell. Softw., 27-28 40-51.

Vezzaro,L., Eriksson,E., Ledin,A., Mikkelsen,P.S., 2010. Dynamic stormwater treatment unit model for micropollutants (STUMP) based on substance inherent properties. Water Sci. Technol., 62, 622-629.

Vezzaro,L., Eriksson,E., Ledin,A., Mikkelsen,P.S., 2011. Modelling the fate of organic micropollutants in stormwater ponds. Sci. Tot. Environ., 409, 2597-2606.

Vezzaro,L., Ledin,A., Mikkelsen,P.S., 2012. Integrated modeling of priority pollutants in stormwater systems. Phys. Chem. Earth, , 42-44, 42-51.

Vezzaro, L., Mikkelsen, P. S., Deletic, A., McCarthy, D. T., 2013. Urban drainage models simplifying uncertainty analysis for practitioners. Water Sci. Technol., 68, 2136-2143

Vollertsen,J., Lange,K.H., Pedersen,J., Hallager,P., Bruus,A., Laustsen,A., Bundesen,V.W., Brix,H., Nielsen,A.H., Nielsen,N.H., Wium-Andersen,T., Hvitved-Jacobsen,T., 2009. Monitoring the startup of a wet detention pond equipped with sand filters and sorption filters. Water Sci. Technol., 60, 1071-1079.

Vrugt,J.A., Gupta,H.V., Bouten,W., Sorooshian,S., 2003. A Shuffled Complex Evolution Metropolis algorithm for optimization and uncertainty assessment of hydrologic model parameters. Water Resour. Res., 38, SWC11-SWC116.

Wium-Andersen,T., Nielsen,A.H., Hvitved-Jakobsen,T., Vollertsen,J., 2011. Heavy metals, PAHs and toxicity in stormwater wet detention ponds. Water Sci. Technol., 64, 503-511.

Zgheib,S., Moilleron,R., Chebbo,G., 2012. Priority pollutants in urban stormwater: Part 1Case of separate storm sewers. Water Res., 46, 6683-6692. 
Vezzaro, L., Sharma, A. K., Ledin, A., \& Mikkelsen, P. S. (2015). Evaluation of stormwater micropollutant source control and end-of-pipe control strategies using an uncertainty-calibrated integrated dynamic simulation model. Journal of Environmental Management, $151,56-64$. doi:10.1016/j.jenvman.2014.12.013

Zhang,W., Ye,Y., Tong,Y., Ou,L., Hu,D., Wang,X., 2011. Modeling time-dependent toxicity to aquatic organisms from pulsed exposure of PAHs in urban road runoff. Environ. Pollut., $159,503-508$ 
Supplementary information for evaluation of stormwater micropollutant source control and end-of-pipe control strategies using an uncertainty-calibrated integrated dynamic simulation model

Authors: L. Vezzaro, A. K. Sharma, A. Ledin and P.S Mikkelsen
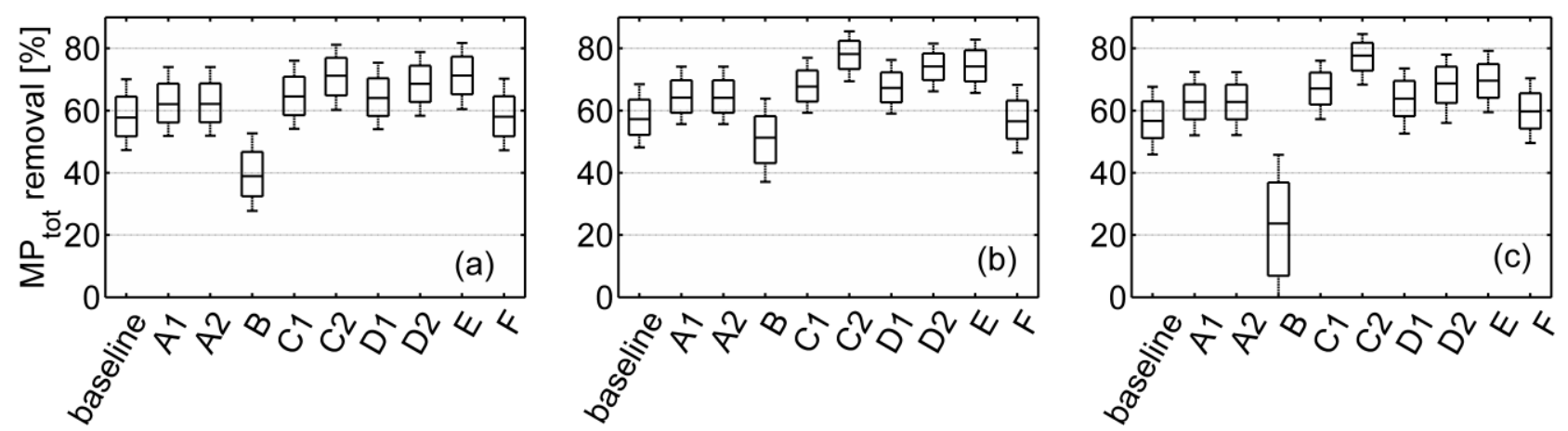

Figure S1. Comparison of simulated $\mathrm{MP}_{\text {tot }}$ removal efficiency in the pond (percentage value of total inlet load) for different scenarios: $\mathrm{Cu}$ (a), $\mathrm{Zn}(\mathrm{b})$ and fluoranthene (c).
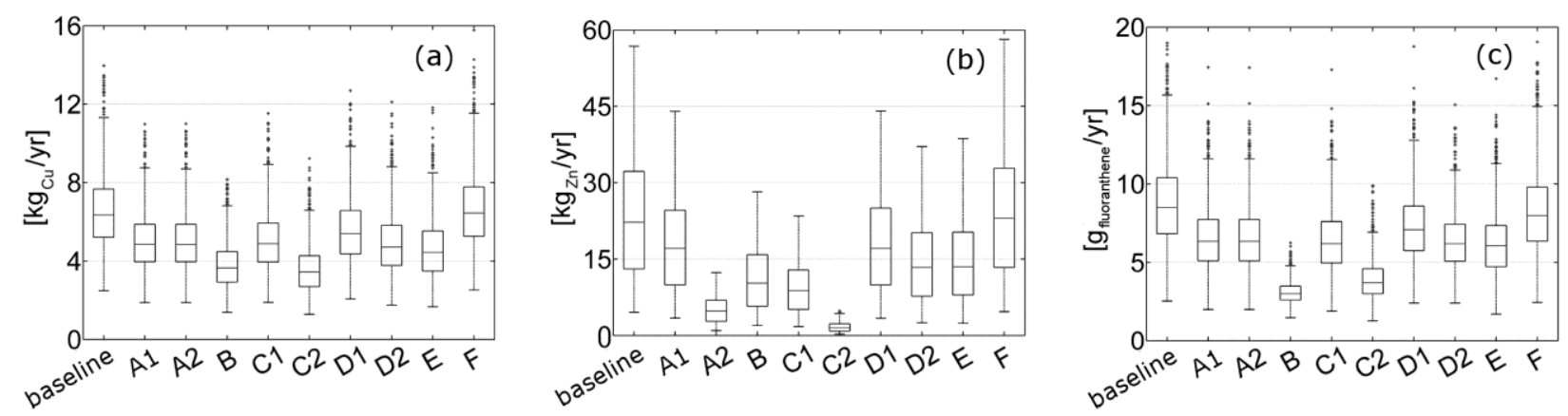

Figure S2. Simulated yearly loads at the pond outlet for the baseline and the six future scenarios for $\mathrm{Cu}(\mathrm{a}), \mathrm{Zn}(\mathrm{b})$ and fluoranthene (c). 


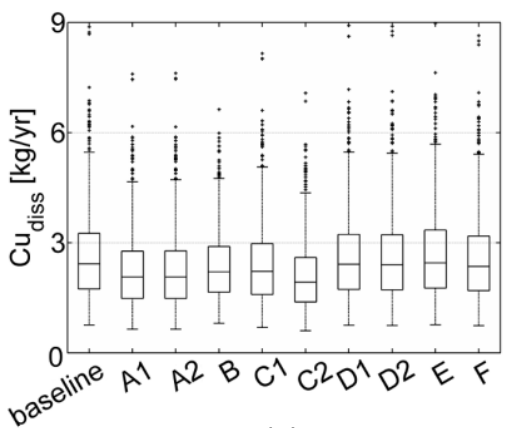

(a)

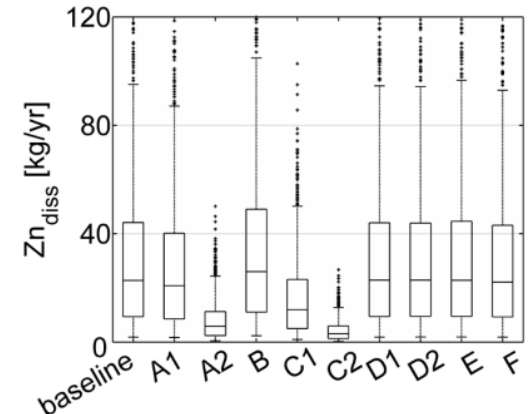

(b)

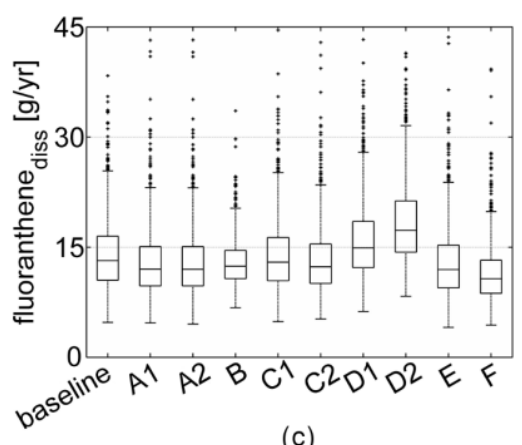

(c)

Figure S3. Comparison of simulated yearly loads for dissolved MP for different scenarios: $\mathrm{Cu}$ (a), Zn (b) and fluoranthene (c).

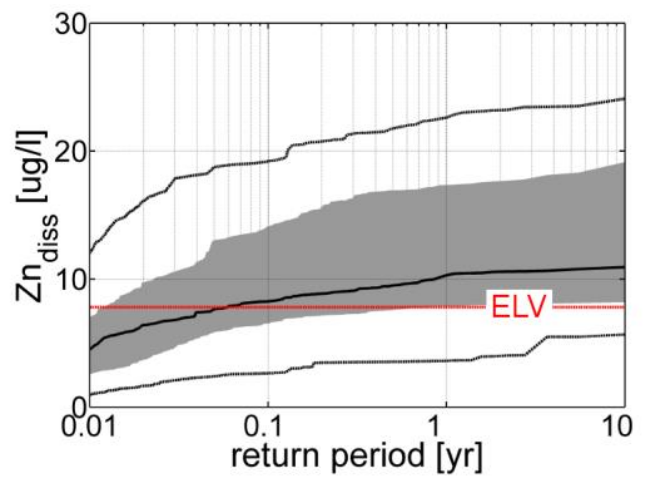

(a)

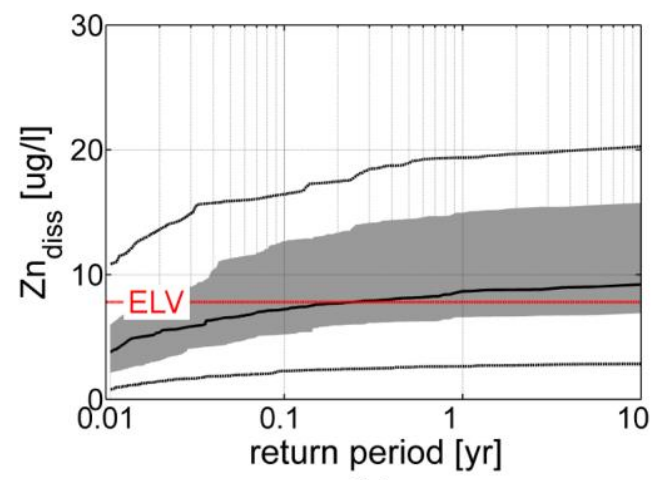

(b)

median

$25 \%-75 \%$ interval

5\%-95\% interval

Figure S4. Simulated dissolved outlet event mean concentrations (EMC) against return period compared with ELV for dissolved Zn (ELV $12 \mu \mathrm{g} / \mathrm{l}$ ), for scenario A2 (a) and C2 (b). 